\title{
ANE syndrome
}

INSERM

\section{Source}

INSERM. (1999). Orphanet: an online rare disease and orphan drug data base. ANE syndrome. ORPHA:157954

ANE syndrome is a rare, genetic, neuro-endocrino-cutaneous disorder characterized by highly variable degrees of alopecia, moderate to severe intellectual disability, progressive, late-onset motor deterioration and combined anterior pituitary hormone deficiency, manifesting with central hypogonadotropic hypogonadism, delayed or absent puberty, growth hormone deficiency (resulting in short stature), progressive central adrenal insufficiency and a hypoplastic anterior pituitary gland. Additional features include hypodontia, flexural reticulate hyperpigmentation, gynecomastia, microcephaly and kyphoscoliosis. 